\title{
STEMI Secondary to Coronary Vasospasm: Possible Adverse Event of Methylphenidate in a 21-Year-Old Man with ADHD
}

\author{
Timo-Benjamin Baumeister ${ }^{1}$ Ingo Wickenbrock ${ }^{1} \cdot$ Christian A. Perings $^{1}$
}

Published online: 23 September 2016

(c) The Author(s) 2016. This article is published with open access at Springerlink.com

\begin{abstract}
Methylphenidate $\left(\operatorname{Ritalin}^{\circledR}\right)$ is an increasingly used medication in the treatment of attention-deficit hyperactivity disorder (ADHD). Cardiovascular adverse effects like vasospasm or myocardial infarction are described as very rare adverse effects. We present the case of a 21-year-old man diagnosed with ADHD who recently started therapy with Ritalin ${ }^{\circledR}$ Adult $20 \mathrm{mg}$ for at least 3 days. Afterwards he presented with chest pain, elevated troponin and creatine kinase, and posterolateral ST elevations. A myocarditis was initially supposed. In the coronary angiography, signs of coronary artery spasm could be found. The echocardiography showed mild left ventricular dysfunction; no acute myocarditis could be found in the cardiac MRI and myocardial biopsy. The medication with methylphenidate was stopped, and after 12 days the asymptomatic patient was discharged from hospital.
\end{abstract}

Timo-Benjamin Baumeister

Timo-Baumeister@gmx.de

1 Medizinische Klinik I, Abteilung für Kardiologie, Elektrophysiologie, Pneumologie und konservative Intensivmedizin, Klinikum Lünen, Altstadtstraße 23, 44534 Lünen, Germany

\section{Key Points}

Methylphenidate contains an existent risk for cardiovascular adverse effects, especially in patients with pre-existing cardiovascular diseases.

Pharmacological interactions seem to be very relevant in the treatment with this medication.

An appropriate pretreatment evaluation and cardiovascular assessment is recommended before starting a therapy with methylphenidate.

\section{Introduction}

Methylphenidate $\quad\left(\right.$ Ritalin $^{\circledR}, \quad$ Novartis Pharmaceutical Corp.) is an increasingly used medication in the treatment of attention-deficit hyperactivity disorder (ADHD). The dopamine and norepinephrine transporters are inhibited by methylphenidate, therefore the second messenger levels rise up in the synaptic cleft (re-uptake inhibition) [1]. The sympathicotonus becomes more active. Cardiovascular adverse effects are mentioned in the summary of product characteristics (SPC): arrhythmia, tachycardia palpitations $(\geq 1 / 100$ to $<1 / 10)$; chest pain $(\geq 1 / 1000$ to $<1 / 100)$; angina pectoris $(\geq 1 / 10,000$ to $<1 / 1000)$; cardiac arrest, myocardial infarction $(<1 / 10,000)$.

\section{Case Presentation}

A 21-year-old man presented to an accident and emergency department on a Sunday morning. Starting the evening before, he had acute chest pain that persisted till the 
morning. Apart from smoking (1.5 pack-years), no other cardiovascular risk factors could be detected. Known comorbidities were bronchial asthma, coeliac disease, depression and ADHD. ADHD was diagnosed 6 years before. His current medication was citalopram $10 \mathrm{mg}$ (Cipramil ${ }^{\circledR} 10 \mathrm{mg}$ ), a selective serotonin reuptake inhibitor (SSRI), once daily, for about 2 years (noncontinuous) and methylphenidate $20 \mathrm{mg}$ (Ritalin ${ }^{\circledR}$ Adult $20 \mathrm{mg}$ ) once daily. He had just recently started therapy with methylphenidate (3 days ago). Methylphenidate was started because of progressive problems regarding attention deficits. There was no ADHD-specific medication in the past (just behaviour therapy) and there was no specific medication for his bronchial asthma or the coeliac disease. Excepting his new medication, no other medically relevant events during the last weeks (infections etc.) were reported. Ritalin ${ }^{\circledR}$ Adult has been labelled for use in adult ADHD patients in Germany since 2014 .

In the accident and emergency department, a clinical examination, an electrocardiogram (ECG) and a blood sample were performed. The results of the physical examination were without pathological findings, the vital signs were normal (blood pressure $117 / 63 \mathrm{mmHg}$, heart rate $53 / \mathrm{min}$, temperature $36.9{ }^{\circ} \mathrm{C}$ ). The ECG showed ST elevations in II, III, aVF, $(0.1 \mathrm{mV})$ and V4-6 $(0.2 \mathrm{mV})$ (Fig. 1). The troponin rapid test was positive. Therefore, the patient was immediately transferred to our accident and emergency department because of the diagnosed ST elevation myocardial infarction (STEMI). The ECG results were confirmed in the blood sample, where highly elevated troponin and creatine kinase (CK) could be detected (troponin 990 pg/mL; CK 1068 U/L [CK-MB

Fig. 1 Electrocardiography day 1; ST elevations II, III, aVF, $\mathrm{V} 4-6 ; 50 \mathrm{~mm} / \mathrm{s}, 10 \mathrm{~mm} / \mathrm{mV}$; GE MAC 2000

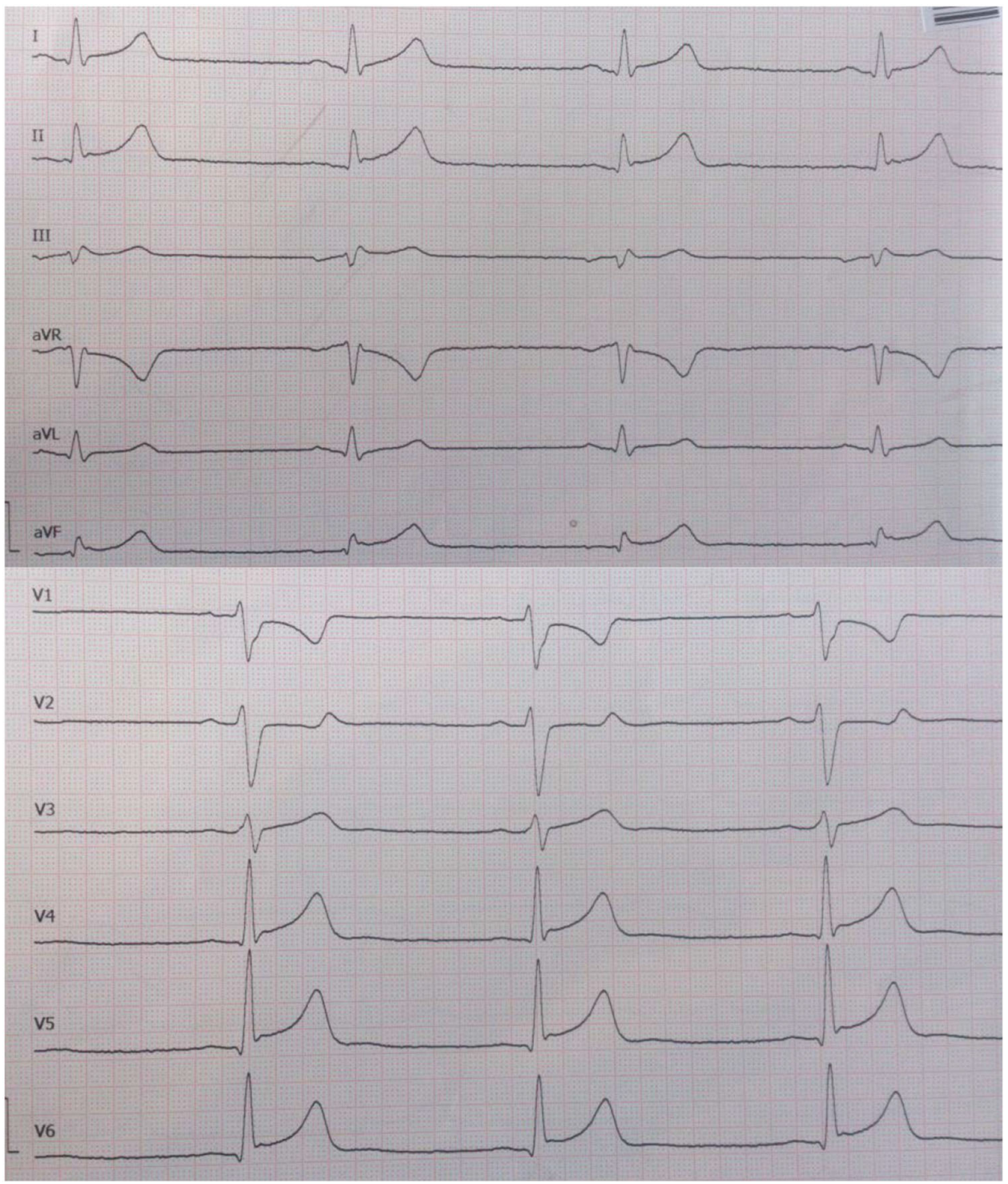




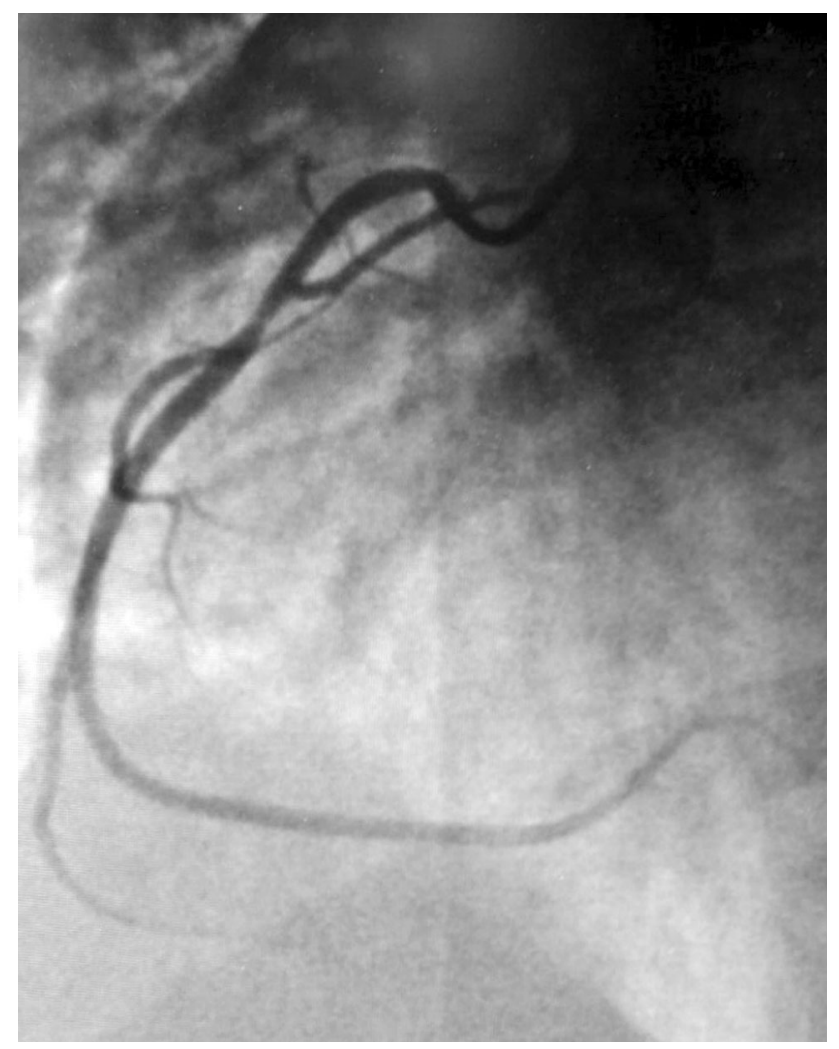

Fig. 2 Coronary angiography; coronary vasospasm proximal right coronary artery

$89 \mathrm{U} / \mathrm{L}])$. At the first contact hospital the patient was given morphine $2.5 \mathrm{mg}$, acetylsalicylic acid $500 \mathrm{mg}$ and heparin $5000 \mathrm{IU}$, intravenously. Afterwards, the chest pain decreased rapidly. Before performing the coronary angiography in our department, $60 \mathrm{mg}$ prasugrel $\left(\right.$ Efient $^{\mathbb{B}}$ ) was given orally as a starting dose. Percutaneous coronary angiography was immediately performed. Apart from signs of a coronary vasospasm in segment 1 of the right coronary artery (RCA) (Fig. 2), the coronary arteries were normal. Regular conditions regarding supply area of coronary arteries could be detected. An acetylcholine spasm provocation test was not performed. After the coronary angiography, the patient was monitored in our Intermediate Care Unit. In the orienting echocardiography, a mildly reduced left ventricular ejection fraction (EF $49 \%$ ) could be seen.

During the next 4 days in the Intermediate Care Unit, the patient remained stable and asymptomatic. A daily oral dose of acetylsalicylic acid $100 \mathrm{mg}$ (ASS $100 \mathrm{mg} \mathrm{Hexal}{ }^{\circledR}$ ) was given. CK elevated to $1800 \mathrm{U} / \mathrm{L}$ (CK-MB $98 \mathrm{U} / \mathrm{L})$ on the second day of observation and then decreased successively to normal values. Troponin fluctuated around $900 \mathrm{pg} / \mathrm{mL}$ for the following 5 days, and then decreased too. The ECG normalised within the first 48 hours after onset of chest pain (Fig. 3).
The urine toxicological testing was positive for tetrahydrocannabinol (THC). The patient admitted that he consumed cannabis 2 days before his admission to hospital. THC had been sporadically consumed by the patient in the past.

Because of the diagnostic results, the initial differential diagnosis was myocarditis. A myocardial biopsy was performed. The histological analysis of the myocardial tissue demonstrated no active acute myocarditis. Only a moderate atrophy of cardiomyocytes indirectly indicated a prolonged or already past myocardial impairment process and was therefore compatible to a status after myocarditis. Only a low viral load (106 viral copies/ $\mu \mathrm{g}$, Erythrovirus genotype 1, 40 mRNA copies) was found. The cardiac MRI showed no signs of acute myocarditis. The echocardiographic examination before discharge showed a return to a normal left ventricular function (EF $66 \%$ ).

Consequently, acute myocarditis as the reason for the patients' symptoms and our diagnostic findings was not reasonable. We suggested that the STEMI was induced by a coronary vasospasm because of methylphenidate, as we could see in our performed coronary angiography. The medication with methylphenidate was stopped. In a telephone follow-up 1 week after discharge from hospital, the patient still had no more symptoms.

\section{Discussion}

Methylphenidate is used in the treatment of ADHD as the first-line therapy. The incidence of prescribing methylphenidate for ADHD has shown a significant increase in recent years, due to widespread diagnosis of the disorder. Although relevant cardiovascular events have been seen in some studies [2], no causal relationship with methylphenidate could be proved. Similarly, there were recently published case reports [3, 4] in which patients had a STEMI while they were taking methylphenidate.

Regarding the Naranjo Algorithm-Adverse Drug Reaction Probability Score, a total score of 4 points was reached in our case. A total score of 1-4 describes a 'possible' adverse drug reaction probability. A total score of 5-8 indicates a 'probable' reaction, and a score of 9-13 a 'definite' probability. At least a 'possible' adverse event can be seen in our case.

The adrenergic effect of methylphenidate may have clinical impact, especially for individual patients with underlying heart disease. Therefore, it is not surprising that in many studies, an increase in heart rate and blood pressure was observed [5]. Increased cardiac stress is the result.

Regarding the interaction of methyphendiate and citalopram, methylphenidate may inhibit the metabolism of SSRIs, causing elevated SSRI plasma concentrations [6]. 
Fig. 3 Electrocardiography day 2; T-negativity III, aVF, V3-5; $50 \mathrm{~mm} / \mathrm{s}, 10 \mathrm{~mm} / \mathrm{mV}$; GE MAC 1200

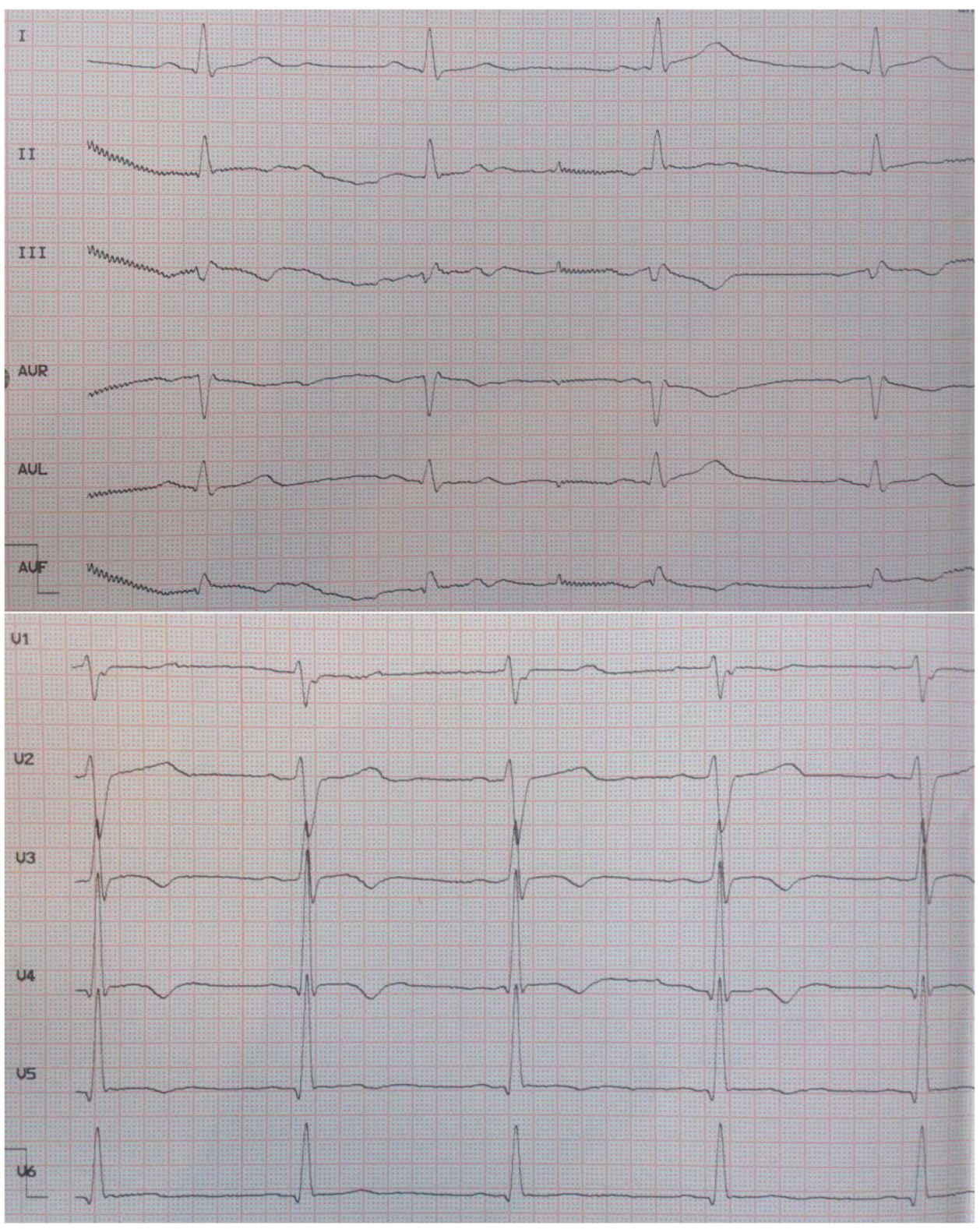

Higher plasma serotonin levels and therefore an increased serotonergic activity could influence the onset of coronary artery spasm [7].

In our case, methylphenidate might be assumed to have induced a coronary spasm as an early adverse effect, which caused the STEMI [8]. The reduced left ventricular function in the acute phase is most likely due to vasospasmrelated hibernating myocardium; thus also explaining the rapid convalescence within a few days.

In this case, we assume that the young patient had been through latent myocarditis some time before. This assumption is based on the results of the myocardial biopsy. There are some case reports describing a higher rate of coronary vasospasm due to acute myocarditis. Acute myocarditis can change coronary vasomotility, induce endothelial dysfunction and lead to coronary vasospasm $[9,10]$. Because of the past myocarditis, there might be a higher sensitivity of the coronary arteries regarding vasoactive substances like methylphenidate. Nevertheless, the disruption of the coronary autonomic balance in favour of coronary vasoconstriction might be influenced by other risk factors such as THC use and smoking. The use of THC might have been a co-factor regarding the coronary spasm, but because of the significant delay of symptom onset, a direct relationship seems to be implausible. There are some case reports describing a relationship between cannabis and coronary vasospasm, but are often related to heavy cannabis smokers [11]. Our patient denied regular or heavy abuse of THC. The quite low amount of cigarettes per day ( $1 / 4$ pack per day over 
6 years; 1.5 pack-years) seems unremarkable as a main reason for vasospasm in this case.

Unfortunately, no acetylcholine spasm provocation test was done during the urgently performed coronary angiography. It might have provided evidence for elevated potential regarding coronary vasospasm in our patient. However, we would have no proof for a direct relationship between higher coronary vasospasm potential and the use of methylphenidate. Other factors might have had an influence on the results of the acetylcholine provocation test (e.g., as mentioned, latent myocarditis, THC, SSRI).

There have been a few large retrospective cohort studies which found no evidence for a significantly higher risk of cardiovascular adverse effects for methylphenidate $[2,12,13]$. However, the statistical power was limited in those studies as the absolute risk of cardiovascular events is quite low in children and adolescents. Also, the issue of relevant co-medication was hardly addressed in these studies. A systematic review conducted in 2014 showed that adverse effects from methylphenidate for adults with ADHD were not of serious clinical significance [14]. The most pronounced adverse reactions noted were a decrease in appetite, weight loss and mild moodiness. Five studies of this review reported a rise in blood pressure and three described a rise in heart rate. These results were judged to present no cause for concern. Nevertheless, there have been a few case reports indicating a probability for cardiovascular events while using methylphenidate. Thompson and Thompson [3] described the case of a 27-year-old man who suffered a myocardial infarction due to a coronary vasospasm related to the use of methylphenidate complicated by concomitant use of pseudoephedrine. Ruwald et al. [4] reported a case of a 20 -year-old man who had a STEMI because of methylphenidate overdose. One of the latest studies is a nationwide self-controlled case-series study from South Korea [15]. Regarding myocardial infarction, no significant risk for all exposed time periods could be found, but risk was higher in the early risk periods after start of treatment with methylphenidate (first 2 months). These findings in a cohort of 1224 patients are in line with our case.

We conclude that before introducing a methylphenidatebased medication, patients should undergo cardiac evaluation because of the risk of cardiovascular events. A reasonable awareness of cardiovascular risk potential of methylphenidate is necessary for the physicians and their patients and an appropriate pretreatment evaluation is recommended [16]. Possible risk factors like cardiovascular ones or drug abuse (cocaine, THC, etc.) should be excluded.

The probability for inducing cardiac side effects with methylphenidate might be larger in patients with existing cardiac comorbidities and/or with a relevant comedication (e.g. SSRI). Therefore, the administration of methylphenidate to patients with cardiovascular history and/ or concomitant medication should be carefully checked.

One week after discharge from hospital, the patient reported no further complaints after discontinuation of the methylphenidate medication. Therefore, a correlation between the sudden onset of the complaint and start of medication seems likely.

This is one of the first case reports reporting an acute myocardial infarction because of a coronary artery spasm in a young man as a possible early adverse effect of methylphenidate. Even a dosage of $20 \mathrm{mg}$ per day (maximum daily dose $80 \mathrm{mg}$ ) might be sufficient to induce this event after only a short duration of ingestion. Possible cofactors like latent myocarditis, concomitant SSRI medication and effect of THC may also have influenced this event.

\section{Compliance with ethical standards}

Conflict of interest Timo-Benjamin Baumeister, Ingo Wickenbrock and Christian Perings declare that they have no conflicts of interest.

Consent Written informed consent was obtained from the patient for publication of this case report. A copy of the written consent is available for review by the corresponding author of this article.

Study funding statement No financial support was received for the preparation of this manuscript.

Open Access This article is distributed under the terms of the Creative Commons Attribution-NonCommercial 4.0 International License (http://creativecommons.org/licenses/by-nc/4.0/), which permits any noncommercial use, distribution, and reproduction in any medium, provided you give appropriate credit to the original author(s) and the source, provide a link to the Creative Commons license, and indicate if changes were made.

\section{References}

1. Markowitz JS, Patrick KS. Pharmacokinetic and pharmacodynamics drug interactions in the treatment of attention-deficit disorder. Clin Pharmacokinet. 2001;40:753-72.

2. Schelleman H, Bilker WB, Kimmel SE, Daniel GW, Newcomb C, Guevara JP, Cziraky MJ, Strom BL, Hennessy S. Methylphenidate and risk of serious cardiovascular events in adults. Am J Psychiatry. 2012;169:178-85.

3. Thompson J, Thompson JR. Acute myocardial infarction related to methylphenidate for adult attention deficit disorder. J Emerg Med. 2010;38:18-21.

4. Ruwald MH, Ruwald AC, Tonder N. Methylphenidate induced ST elevation acute myocardial infarction. Ugeskr Laeger. 2012;174:647-8.

5. Lamberti M, Italiano D, Guerriero L, D'Amico G, Siracusano R, Ingrassia M, Germanò E, Calabrò MP, Spina E, Gagliano A. Evaluation of acute cardiovascular effects of immediate-release methylphenidate in children and adolescents with attention-deficit hyperactivity disorder. Neuropsychiatr Dis Treat. 2015;11: 1169-74.

6. Nevels RM, Weiss NH, Killebrew AE, Gontkovsky ST. Methylphenidate and its under-recognized, under-explained, and 
serious drug interactions: a review of the literature with heightened concerns. Ger J Psychiatry. 2013;16:29-42.

7. Acikel S, Dogan M, Sari M, Kilic H, Akdemir R. Prinzmetalvariant angina in a patient using zolmitriptan and citalopram. Am J Emerg Med. 2010;28:257.

8. Stern S, Bayes de Luna A. Coronary artery spasm: a, 2009 update. Circulation. 2009;2009(119):2531-4.

9. McCully RB, Cooper LT, Schreiter S. Coronary artery spasm in lymphocytic myocarditis: a rare cause of acute myocardial infarction. Heart. 2005;91:202.

10. Silva D, Marques P, Martins S, Bordalo E, Sá AL, Nóbrega J, Duarte J, Almeida AG, Gabriel HM, Correia MJ, Diogo AN. Coronary artery vasospasm and acute myocarditis: a rare association. Rev Port Cardiol. 2010;29:1879-88.

11. Ghannem M, Belhadj I, Tritar A, Moukala T, Amri N, Noury A, Zaghdoudi M. Cannabis and acute coronary syndrome with ST segment elevation. Ann Cardiol Angeiol. 2013;62:424-8.

12. Cooper WO, Habel LA, Sox CM, Chan KA, Arbogast PG, Cheetham TC, Murray KT, Quinn VP, Stein CM, Callahan ST,
Fireman BH, Fish FA, Kirshner HS, O`Duffy A, Connel FA, Ray WA. ADHD drugs and serious cardiovascular events in children and young adults. N Engl J Med. 2011;365:1896-904.

13. Winterstein AG, Gerhard T, Shuster J, Johnson M, Zito JM, Saidi A. Cardiac safety of central nervous system stimulants in children and adolescents with attention-deficit/hyperactivity disorder. Pediatrics. 2007;120:1494-501.

14. Epstein T, Patsopoulos NA, Weiser M. Immediate-release methylphenidate for attention deficit hyperactivity disorder (ADHD) in adults. Cochrane Database Syst Rev. 2014;18: CD005041.

15. Shin JY, Roughead EE, Park BJ, Pratt NL. Cardiovascular safety of methylphenidate among children and young people with attention-deficit/hyperactivity disorder (ADHD): nationwide self controlled case series study. BMJ. 2016;353:i2550.

16. Bange F, Le Heuzey MF, Acquaviva E, Delorme R, Mouren MC. Cardiovascular risks and management during Attention Deficit Hyperactivity Disorder treatment with methylphenidate. Arch Pediatr. 2014;21:108-12. 